\title{
Editorial
}

Acta Haematol 2006;115:137-140

DOI: $10.1159 / 000090926$

\section{Bleeding and Thrombosis Issues in Pediatric Patients: Current Approach to Diagnosis and Treatment}

\author{
Gili Kenet $^{a}$ Ulrike Nowak-Göttl ${ }^{\mathrm{b}}$ \\ a Pediatric Coagulation Service, National Hemophilia Center and Institute of Thrombosis and Hemostasis, \\ Sheba Medical Center, Tel Hashomer, Israel; ${ }^{b}$ Department of Paediatric Haematology and Oncology, \\ University of Münster, Münster, Germany
}

Hemostasis is a dynamic process which begins in utero. Coagulation factors are synthesized by fetuses by 10 weeks' gestational age and their concentrations gradually increase, being physiologically lower in premature infants as compared to full-term babies or healthy children [1-4].

In the neonate, plasma concentrations of vitamin Kdependent coagulation factors (II, VII, IX, X) and contact factors (XI, XII, prekallikrein and high-molecular-weight kininogen) are about 50\% of adult values [4]. Furthermore, the capacity of newborns to generate thrombin, dependent upon plasma concentrations of procoagulants, is reduced $[5,6]$. These facts, theoretically increasing the risk of severe bleeding, are balanced by the protective effects of physiological deficiencies of the inhibitors of coagulation, as well as by the decreased fibrinolytic capacity in infants $[4,7]$.

In this special issue Chan and his colleagues discuss the phenomenon of reduced plasmin generation in neonates as compared to adults and the lower inhibitory antifibrinolytic effect of lipoprotein on neonatal as compared to adult plasma. The latter may stem from physiologically reduced plasminogen concentrations. Decreased neonatal fibrinolysis potentially increases the risk of perinatal thrombosis, which may require the use of thrombolytic therapy.

The clinical presentation of bleeding disorders in infants is characterized by one or more of the following symptoms: cephalhematomas, injury-related bleeding and bleeding into the skin, manifesting as petechiae, purpura and ecchymoses. Persistent oozing from the umbilical stump is typical for infants with defective fibrinogen production or function and FXIII deficiency. Joint hemarthroses, typical for severe hemophilias, rarely occur before ambulation. A small proportion of infants with severe coagulation factor deficiencies may present with intracranial hemorrhage as the first manifestation [8-10].

Laboratory variations of hemostatic tests may make it difficult to establish any diagnosis of bleeding disorder in infants [1-4].

Diagnostic problems of special concern are the need to adapt all coagulation assays for small amounts of blood and the age-related interpretation required for test results. The prolonged PT in neonates reflects decreased plasma concentrations of vitamin K-dependent factors, whereas the prolonged PTT stems from decreased plasma levels of contact factors as well [2-4]. The levels of FVIII, FV and FXIII correlate well with adult boundaries. Plasma concentrations of fibrinogen may be skewed upwards, despite the fact that thrombin clotting time may be prolonged, due to a normally present 'fetal' fibrinogen [11]. Bleeding time is shorter in healthy neonates as compared to adults, probably because of increased concentrations and enhanced function of von Willebrand factor (VWF) and VWF large multimers [2-4, 12], increased hematocrit and the presence of large red cells. The platelet num-

\section{KARGER}

Fax +4161306 1234 E-Mail karger@karger.ch www.karger.com
(C) 2006 S. Karger AG, Basel

$0001-5792 / 06 / 1154-0137 \$ 23.50 / 0$

Accessible online at: www.karger.com/aha
Gili Kenet, MD

Pediatric Coagulation Service, National Hemophilia Center and Institute of Thrombosis and Hemostasis, Sheba Medical Center Tel Hashomer, 52621 (Israel)

Tel. +97235302120, Fax +9723535 1806, E-Mail gili.kenet@sheba.health.gov.il 
ber of neonates is within adult limits; however, the evaluation of platelet function is difficult and deserves special attention. Neonatal platelets were found to be hyporeactive in some studies. Some of the reasons reported are decreased receptors, deficient thromboxane synthesis and impaired signal transduction $[8,13,14]$. In this special issue Yael Levy-Shraga and her colleagues report the use of a modified, relatively new technique and device, the cone and platelet analyzer (CPA) as a rapid, feasible mode to assess shear-induced neonatal platelet aggregation. CPA values of preterm and term infants tested in whole cord blood correlated with gestational age; however, the clinical correlation and the predictive value of the test remain to be elucidated. Maayan-Metzger et al. in their manuscript aimed at defining the impact of maternal selective serotonin reuptake inhibitor therapy that may potentially impair platelet function of neonates, using CPA platelet function tests to compare the neonates of treated mothers versus controls; neither bleeding manifestations nor platelet function CPA impairments were found in this study.

Among severe congenital factor deficiencies the representative and mostly reported disorder is hemophilia. Children with hemophilia may present with variable bleeding tendencies requiring a 'tailored' therapeutic approach $[15,16]$. In the review by Amy Dunn and Thomas Abshire therapy considerations in children with hemophilia are discussed, including a description of coagulation factor concentrates currently available and suggestive guidelines for prophylactic therapy. Guy Young, in another manuscript of our special issue, reflects on the challenge of treating hemophilia patients with inhibitors. Inhibitor prevention is discussed and therapy with bypassing agents and novel drugs for bleeding episodes as well as prophylaxis is suggested with potential modes of monitoring treatment outcome.

Prenatal diagnosis of most severe congenital factor deficiencies is currently possible. Thus in families with a history of hemophilia prevention is available since fetal DNA, obtained through amniocentesis or chorionic villi biopsy, can be tested for the presence of known mutations or analyzed to compare linkage and sequences against the sick patient and his parents. Early diagnosis allows for termination of pregnancy or proceeding towards early intervention and therapy, as indicated. With regard to future perspectives, the progress of gene therapy trials may yield the best answer for hemophilia within a few years.

Venous and arterial thrombosis are increasingly diagnosed and reported in children. Due to the special properties of the pediatric hemostatic system, thrombotic manifestation occurs in $0.07 / 10,000$ children, 5.3/10,000 pediatric hospital admissions, and 2.4/1,000 admissions of newborns to intensive care units. Neonates are at the highest risk of thromboembolic complications as compared to older children, with a reported annual incidence of 0.5/10,000 live births in Caucasian children, possibly due to the lower concentrations of the physiological inhibitors of the coagulation system along with their markedly reduced fibrinolytic capacity $[17,18]$. The incidence of vascular accidents decreases significantly after the first year of life, with a second peak during puberty and adolescence again associated with reduced fibrinolytic activity [17].

Numerous clinical and environmental conditions, such as peripartal asphyxia, neonatal infections, fetal diabetes, the use of central lines, trauma or surgery, dehydration, malignant diseases, renal diseases, autoimmune diseases, obesity, immobilization, or the intake of oral contraceptives by adolescent girls may result in elevated thrombin generation with subsequent thrombus formation. In addition, various genetic prothrombotic defects, particularly those affecting the physiological anticoagulant systems (antithrombin, protein $\mathrm{C}$ and protein $\mathrm{S}$ deficiencies, the mutation G1691A of coagulation factor $\mathrm{V}$, and the factor II G20210A gene variant) have been established as risk factors for thrombotic events in the white pediatric population [19-24]. Furthermore, moderate hyperhomocysteinemia as well as increased concentrations of lipoprotein (a) and factor VIII have recently been shown to significantly enhance the risk of thromboembolic arterial and venous thrombosis in pediatric and adult patients [25-27]. Nevertheless, until today up to $30-40 \%$ of pediatric patients with symptomatic thromboembolism do not have any identifiable inherited prothrombotic risk factor. Therefore, studies dealing with the association between hemostatic factors and pediatric thromboembolism are of special interest. In this special pediatric issue, population-based data on arterial ischemic stroke and cerebral venous thrombosis in children were summarized by Mariana Bonduell et al. based on a 12-year Argentinean pediatric thrombosis registry. The authors report on underlying inherited and acquired conditions, mortality and recurrence data, as well as clinical outcome rates. Burghaus and co-authors describe in a case-control study that elevated $\alpha_{1}$-antitrypsin increases the risk of arterial ischemic stroke in white children 4.0fold independently from other established thrombophilias. In this controlled study cutoff values above the agedependent 90th percentiles were derived from 229 healthy controls. Danckwardt and co-workers review the patho- 
mechanism of clinically relevant mutations in the factor II gene, which may promote further understanding of the etiology of pediatric thromboembolism.

In a further manuscript dealing with thrombosis epidemiology in selective pediatric high-risk groups, Cyr and colleagues studied the incidence of deep vein thrombosis in children after major trauma. The authors report an incidence of 3.3 per 1,000 admissions diagnosed with symptomatic deep vein thrombosis. In this Canadian cohort thrombosis was more common in older children with high injury severity scores, in patients with thoracic injuries, in children suffering spinal injuries, and in subjects with central venous lines. Shoshana Revel-Vilk reviews central venous line thromboses, comprising a significant risk of venous thromboembolism in pediatric patients. Interestingly, catheter thrombosis in children may be missed, since its reported frequency is as low as 5\% in studies including only symptomatic cases and as high as 50\% in studies where patients are systematically screened for catheter-related thrombosis. The review describes risk factors for catheter-related thrombosis that may be associated with the methods used for catheter insertion as well as individual patient characteristics, and reflects upon diagnosis and treatment.

Postthrombotic syndrome is a definition used to determine thrombotic sequelae in adult patients with deep vein thrombosis. However, it also is increasingly noted in pediatric patients. In her review, Marilyn Manco-Johnson focuses on postthrombotic syndrome in children, highlighting functional tools which can be used in order to accurately assess this problem. In addition, Leo Brandão and his group from Canada report on the specific findings of postthrombotic syndrome following upper limb system thrombosis, mainly occurring in adolescents.
The management of children with acute thrombosis usually comprises therapy with anticoagulants [28, 29]. Thrombolytic agents may be used during acute thrombotic events, and are currently mainly applied in neonates [30], due to the physiologically reduced fibrinolytic capacity of this age group [18]. In pediatric patients with thrombosis, however, antithrombotic treatment protocols cannot automatically be adjusted from adults. In this issue Nick Merkel and colleagues report on a long-term pilot study in pediatric patients with venous thrombosis treated with enoxaparin. In this survey enoxaparin was prescribed twice daily in children, and was found to be safe and effective, especially when the drug was administered over a mean period of time of 10 months. One of the major adverse effects of heparin treatment, heparininduced thrombocytopenia, is well known and may complicate antithrombotic therapy. This severe adverse effect of heparin is more common in adults and has rarely been reported in children. Bidlingmaier and colleagues review the literature available for heparin-induced thrombocytopenia in pediatric patients, including treatment regiments applied in this cohort so far.

Long-term anticoagulant therapy may be required for selected pediatric patients in order to prevent a recurrence of thrombosis [31]. The potentially protective role of secondary prophylaxis in high-risk conditions also deserves further attention in the future.

In summary, the current manuscripts collected in our special issue on pediatric coagulation highlight some of the controversies associated with diagnosis, epidemiology and therapy of bleeding disorders as well as thrombosis in children. Prospective randomized multicenter trials and data collection are warranted in order to improve the understanding and treatment of these disorders.

\section{References}

1 Reverdiau-Moalic P, Delahousse B, Body G, Bardos GBP, Delahousse B, Leroy J, Gruel Y: Evolution of blood coagulation activators and inhibitors in the healthy human fetus. Blood 1996;88:900-906.

2 Andrew M, Paes B, Milner R, Johnston M, Mitchell L, Tollefsen DM, Castle V, Powers P: Development of the human coagulation system in the healthy premature infant. Blood 1988;72:1651-1657.

3 Andrew M, Paes B, Johnston M: Development of the hemostatic system in the neonate and young infant. Am J Pediatr Hematol Oncol 1990;12:95-104.
4 Andrew M, Vegh P, Johnston M, Bowker J, Ofosu F, Mitchell L: Maturation of the hemostatic system during childhood. Blood 1992; 80:1998-2005.

5 Cvirm G, Gallistl S, Muntean W: Effects of antithrombin and protein $\mathrm{C}$ on thrombin generation in newborn and adult plasma. Thromb Res 1999;93:183-190.

6 Andrew M, Schmidt B, Mitchell L, Paes B, Ofosu F: Thrombin generation in newborn plasma is critically dependent on the concentration of prothrombin. Thromb Haemost 1990;63:27-30.
7 Summaria L: Comparison of human normal, full-term, fetal and adult plasminogen by physical and chemical analyses. Haemostasis 1989; 19:266-273.

8 Yoffe G, Buchanan GR: Intracranial hemorrhage in newborn and young infants with hemophilia. J Pediatr 1988;113:333.

9 Abbondanzo SL, Gootenbeg JE, Lofts R, McPherson R: Intracranial hemorrhage in congenital deficiency of FXIII. Am J Pediatr Hematol Oncol 1988;10:65-68.

10 Struwe FE: Intracranial hemorrhage and occlusive hydrocephalus in hereditary bleeding disorders. Dev Med Child Neurol 1970;12: 165 
11 Witt I, Muller H, Kunter LJ: Evidence for the existence of fetal fibrinogen. Thromb Diath Haemorrh 1969;22:101-109.

12 Katz JA, Moake JL, McPherson PD, Weinstein MJ, Moise KJ, Carpenter RJ, Sala DJ: Relationship between human development and disappearance of unusually large von Willebrand factor multimers from plasma. Blood 1989;73:1851-1858.

13 Rajasekar D, Bernard M, Francis J Bednarek F: Platelet hyporeactivity in very low birth weight neonates. Thromb Haemost 1997;77: 1002-1007.

14 Israels SJ, Odaibo FS, Robertson C, McMillan EM, McNicol A: Deficient thromboxane synthesis and response in platelets from premature infants. Pediatr Res 1997;41:218-223.

15 Brettlet D, Levine P: Clinical manifestations and therapy of inherited coagulation factor deficiencies; in Colman RW, Hirsh J, Marder VJ, Salzman EW (eds): Hemostasis and Thrombosis: Basic Principles and Clinical Practice, ed 3. Philadelphia, Lippincott, 1999, pp 169 183.

16 Astermark J, Petrini P, Tengborn L, Schulman S, Ljung R, Berntorp E: Primary prophylaxis in severe haemophilia should be started at an early age but can be individualized. Br J Haematol 1999;105:1109-1113.

17 Andrew M: Developmental hemostasis: relevance to thromboembolic complications in pediatric patients. Thromb Haemost 1995;74: 415-425.
18 Reis M, Klinge J, Rauch R: Age-related reference values for activation markers of the coagulation and fibrinolytic systems in children. Thromb Res 1997;85:341-344.

19 Schmidt B, Andrew M: Neonatal thrombosis: report of a prospective Canadian and international registry. Pediatrics 1995;96:939-943.

20 van Ommen $\mathrm{CH}$, Heijboer $\mathrm{H}$, Buller $\mathrm{HR}$, Hirasing RA, Heijmans HS, Peters M: Venous thromboembolism in childhood: a prospective 2-year registry in the Netherlands. J Pediatr 2001;139:676-681.

21 Heller C, Schobess R, Kurnik K, Junker R, Gunther G, Kreuz W, Nowak-Gottl U: Abdominal venous thrombosis in neonates and infants: role of prothrombotic risk factors - a multi-center case-control study. Br J Haematol 2000;111:534-539.

22 Revel-Vilk S, Chan A, Bauman M, Massicotte P: Prothrombotic conditions in an unselected cohort of children with venous thromboembolic disease. J Thromb Haemost 2003; 1:915921.

23 Ehrenforth S, Junker R, Koch HG, Kreuz W, Munchow N, Scharrer I, Nowak-Gottl U: Multicenter evaluation of combined prothrombotic defects with thrombophilia in childhood. Eur J Pediatr 1999;158:S97-S104.

24 Kenet G, Sadetzki S, Murad H, Martinowitz U, Rosenberg N, Gitel S, Rechavi G, Inbal A Factor V Leiden and antiphospholipid antibodies are significant risk factors for ischemic stroke in children. Stroke 2000;31:12831288 .
25 van Beynum IM, Smeitnik JA, den Heijer M, te Poele Pothoff MT, Blom HJ: Hyperhomocysteinemia: a risk for ischemic stroke in children. Circulation 1999;99:2070-2072.

26 Nowak-Gottl U, Junker P, Hartmeier M, Koch HG, Munchow N, Assmann G, von Eckardstein A: Increased lipoprotein (a) is an important risk factor for venous thrombosis in childhood. Circulation 1999;100:743-748.

27 Goldenberg NA, Knapp-Clevenger R, MancoJohnson M: Elevated plasma factor VIII and D-dimer levels as predictors of poor outcome of thrombosis in children. N Engl J Med 2004; 351:1081-1088.

28 Andrew M, Michelson AD, Bovill E, Leaker M, Massicotte MP: Guidelines for antithrombotic therapy in pediatric patients. J Pediatr 1998 132:575-588.

29 Dix D, Andrew M, Marzinotto V, Charpentier $\mathrm{K}$, Bridge $\mathrm{S}$, Monagle $\mathrm{P}$, deVeber $\mathrm{G}$, Leaker M, Chan AK, Massicotte MP: The use of low molecular weight heparin in pediatric patients: a prospective cohort study. J Pediatr 2000;136: 439-445.

30 Nowak-Gottl U, Auberger K, Halimeh S, Junker R, Klinge J, Kreuz WD, Ries M, Schlegel $\mathrm{N}$ : Thrombolysis in newborns and infants. Thromb Haemost 1999;82:S112-S116.

31 Kurnik K, Koch A, Strater R, Schobess R, Heller C, Nowak-Gottl U: Recurrent thromboembolism in infants and children suffering from symptomatic neonatal arterial stroke: a prospective follow-up study. Stroke 2003;34: 2887-2892. 